\title{
Casa dos Desafios Virtual ${ }^{1}$
}

Eduardo Melloni Lucchesi - eduardo.lucchesi@gmail.com Rodrigo Orestes Feijó - digoorestes@yahoo.com.br Marcus Vinicius de Azevedo Basso - mbasso@ufrgs.br Instituto de Matemática - Universidade Federal do Rio Grande do Sul

\section{Resumo:}

Nesse artigo apresentamos o desenvolvimento de uma interface denominada Casa dos Desafios Virtual como uma alternativa para a inserção dos estudantes no contexto educacional. Ao percorrer as diferentes salas de uma casa/labirinto virtual, desafios vão sendo apresentados ao explorador enquanto este interage com o conteúdo. Para prosseguir pela casa os desafios devem ser resolvidos, mas para isso ele deverá consultar o material de apoio e os guias que estão disponíveis no ambiente, bem como obter ajuda de colegas e professores em questões envolvendo conceitos de biologia e de matemática voltadas aos alunos do ensino médio. $\mathrm{O}$ objeto foi desenvolvido utilizando recursos Java e Flash e sua utilização pode ser feita com ou sem acesso via web.

Palavras - chave: ambiente virtual, objetos de aprendizagem, educação à distância.

Title: House of challenges

\begin{abstract}
:
In this article we present the development of an interface called Virtual Challenge House as an alternative for students' insertion at the educational context. Going trough the different rooms of a virtual house/labyrinth, challenges are presented to the explorer while he interacts with the content. To continue trough the house the challenges must be solved, but to accomplished that the student should look to the support material and the guides available at the ambient, as well as he should get help from the colleagues and teachers about questions involving biology and mathematics concepts directioned for high school students. The object was developed using Java and Flash and it can be used without internet access.
\end{abstract}

Keywords: virtual environment, learning objects, e-learning.

\section{Introdução}

O presente trabalho é uma conseqüência direta das nossas primeiras tentativas de renovar o paradigma escolar do conhecimento pela repetição, linear, massificado, onde o professor é o detentor da verdade. Ou, pelo menos, participarmos das discussões de forma efetiva levando nossa contribuição a escola. Vimos uma oportunidade na proposta da Rede Interativa Virtual de Educação (RIVED) - Fábrica Virtual, que se iniciou em 2004, com a construção de Objetos de Aprendizagem (OA) simultaneamente em diferentes lugares do país. Compartilhando os resultados com os demais participantes que detinham na sua maioria tão pouca experiência quanto nós, fomos nos inserindo no mundo da Tecnologia da Informação e Comunicação.

\footnotetext{
1 Trabalho vinculado ao RIVED - Secretaria de Educação à Distância - Ministério da Educação, desenvolvido sob orientação dos Prof. Marcus Vinicius de Azevedo Basso e Léa Fagundes.
} 
No primeiro momento trabalhamos num OA sobre construção de Mosaicos (Lucchesi at al, 2004) e outras atividades utilizando o Macromedia Flash. Esse objeto e as atividades contempladas por ele foram utilizados com estudantes de $5^{\text {as }}$ e $6^{\text {as }}$ séries do Ensino Fundamental (Lucchesi at al, 2004) do Colégio de Aplicação - Projeto Amora da UFRGS, por alunos da graduação da Licenciatura em Matemática da UFRGS. Tal uso oportunizou aos graduandos a familiaridade com o uso da informática na educação, a familiaridade com o uso do computador em sala de aula, com o acesso a web e os mecanismos de busca e mais atualmente, com o uso de blogs e wikis. Como conseqüência, em alguns casos, esses graduandos se sentiram interessados em aprender a desenvolver de atividades virtuais de maneira original.

Buscando ampliar os trabalhos já desenvolvidos sobre OA, interconectar os OA entre si, e não apenas como links e hiperlinks soltos em determinada página é que se pensou em elaborar um Ambiente Virtual simulando uma ilha com casas, comércio, criação de coelhos, simulações de pesca sustentada entre outros. Inicialmente tratando de conceitos matemáticos e biológicos, mas pensando em ampliar para outras disciplinas futuramente foi planejando um ambiente em que o aprendiz pudesse se deslocar, visitando lugares de sua escolha, realizando experimentos, vendo animações, realizando simulações, tendo um suporte conceitual a disposição para consultar a qualquer momento e contando com os esclarecimentos do professor e as interações com os colegas nessa aventura exploratória de conhecimento.

Dessa forma, buscamos proporcionar ao aluno a construção do conhecimento levando em conta os aspectos citados por (Fagundes at al, 1999):

“(...) para construir conhecimento, é preciso reestruturar as significações anteriores, produzindo boas diferenciações e integrando ao sistema as novas significações. Esta integração é resultado da atividade de diferentes sistemas lógicos do sujeito, que interagem entre si e com os objetos a assimilar ou com os problemas a resolver. Finalmente, o conhecimento novo é produto de atividade intencional, interatividade cognitiva, interação entre os parceiros pensantes, trocas afetivas, investimento de interesses e valores. (...)" (Fagundes, 1999)

\section{Breve descrição do ambiente Acqua}

O ambiente foi denominado Acqua. Ele permite a navegação terrestre, a navegação por um mergulhador e a navegação por submarino nas águas que cercam a ilha. Além disso, disponibiliza por menu, via links rápidos, acesso diretamente a todo o conteúdo dos diferentes módulos sem a necessidade de navegação. O sistema de busca (Acquapedia Figura 1) dos conceitos pode ser chamado pelo menu, mostrando todos os conceitos do Acqua, ou pode ser chamado de dentro dos módulos. Nesse caso, o Acquapedia préseleciona os conceitos relativos ao módulo em que se está trabalhando, mas permite o acesso irrestrito aos demais conceitos, se desejado.

Menu do Ambiente:

Acqua | ambiente terrestre | submarino | mergulhando | links rápidos | acquapedia | equipe 
Se estivermos nos deslocando pelo ambiente terrestre, encontraremos a Casa dos Desafios que descreveremos com mais detalhes na próxima sessão.

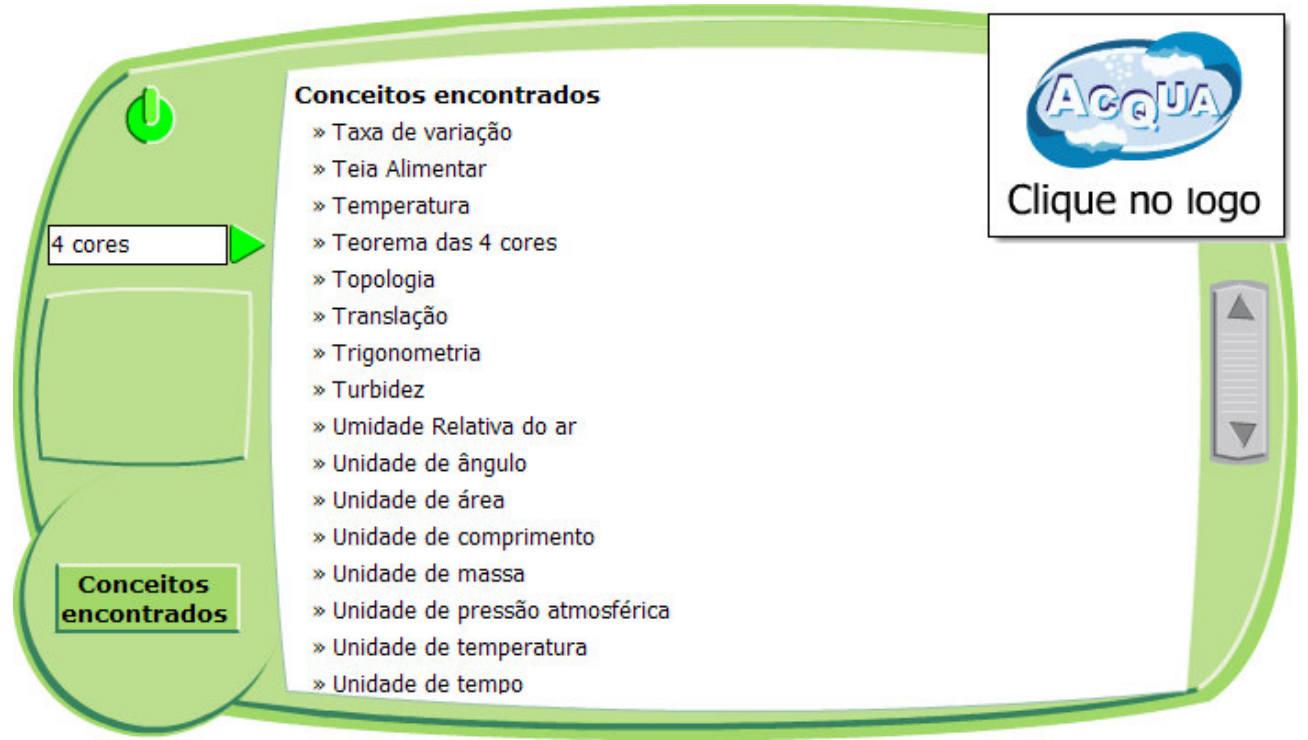

Figura 1: Acquapedia <pesquisa lista de conceitos>

\section{Descrição da Casa dos Desafios}

\subsection{Navegação}

A figura 2 mostra a Casa como se estivéssemos navegando pelo ambiente terrestre. Para entrar, é só clicar na seta marrom que aponta para a entrada da casa.

No menu dos links rápidos, aparece essa mesma figura com o seguinte texto:

Será que você e seus colegas são capazes de resolver os desafios do Acqua? Acreditamos que sim, mas antes disso você terá que encontrálos! Utilizando apenas uma lanterna e da inteligência, solucione os desafios propostos em cada sala e encontre a Sala Secreta de Acqua.

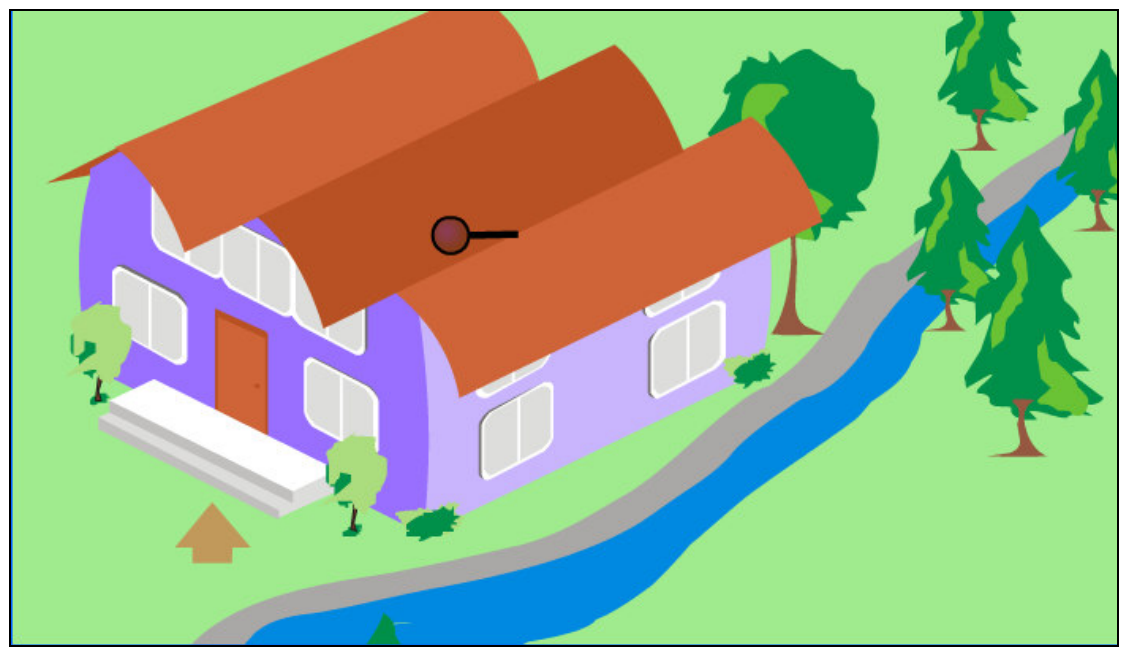

Figura 2: Casa dos Desafios <ambiente terrestre> 
Ao selecionar a seta, se é direcionado a tela de abertura (Figura 3) com o texto a seguir:

Neste objeto você vê a casa com os olhos do personagem (em primeira pessoa). Você se move por ela clicando em flechas encontradas nas laterais da tela. Você pode virar para direita ou para a esquerda e passar pelas portas para acessar outras salas da casa. Em cada sala existe um desafio que pode ser identificado pela imagem de um olho que surge ao passar o cursor do mouse sobre ele. Ao resolver um desafio, uma porta se destranca ou uma chave é fornecida.

Este objeto é uma casa-labirinto repleto de desafios que quando resolvidos liberam o acesso a outras salas. Conduzindo o personagem por um ambiente repleto de desafios até Sala Secreta de Acqua.

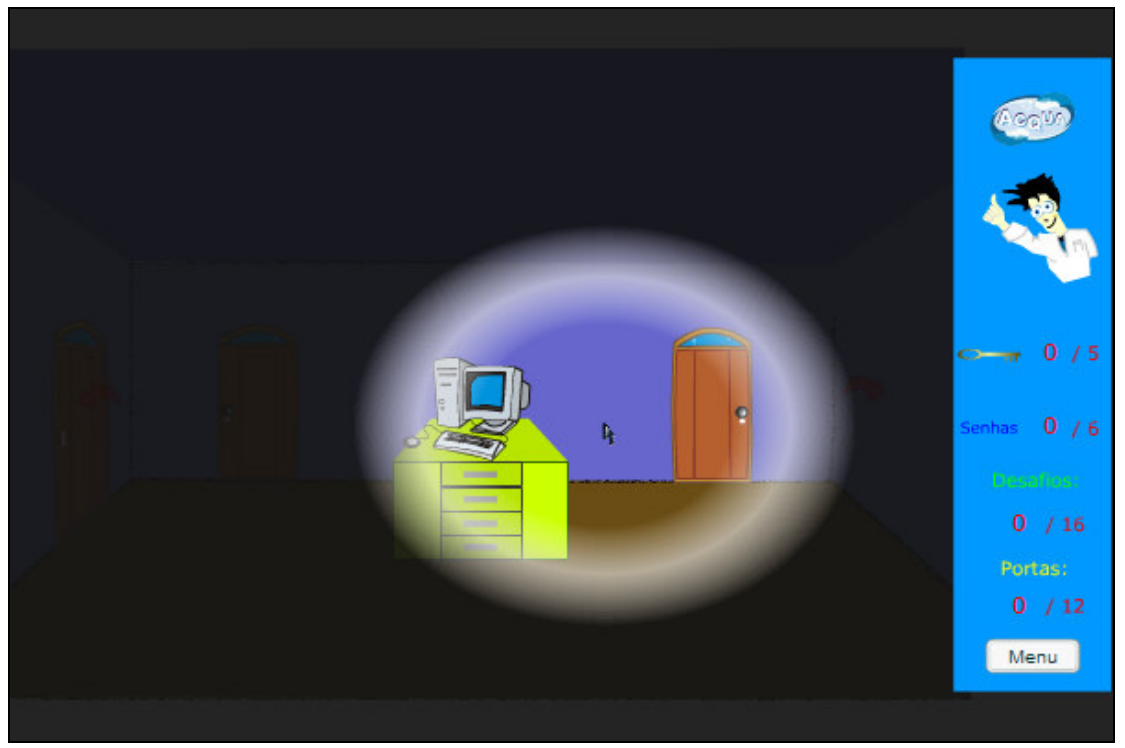

Figura 3: Sala de entrada

Ao chegar à entrada, informações adicionais de navegação e outras dicas são fornecidas pelo Professor Eugênio, que pode ser acionado a qualquer momento, pois o menu azul, à direita, fica sempre visível.

- No fundo, uma porta que está trancada e um computador que levará ao desafio (Figura 3) que, ao ser resolvido, fornecerá a chave da porta;

- acima do Prof. Eugênio, o ícone que lista os conceitos da casa e que chama o Acquapedia;

- ainda pode ser visto um botão <Menu>. Ele chama o mapa da casa. Pelo mapa (Figura 4) se sabe em que sala se está, quais as portas da sala estão liberadas e qual a orientação do usuário representado por um pequeno triângulo vermelho;

- na figura 4, nem todas as salas estão visíveis, pois ainda não foram visitadas;

- os pequenos retângulos azuis representam as janelas e os retângulos verdes, as portas liberadas;

- as portas trancadas são indicadas por retângulos vermelhos;

- as portas liberadas uma vez podem ser todas abertas novamente numa próxima jogada desde que uma senha seja gerada e usada nas vezes seguintes. 


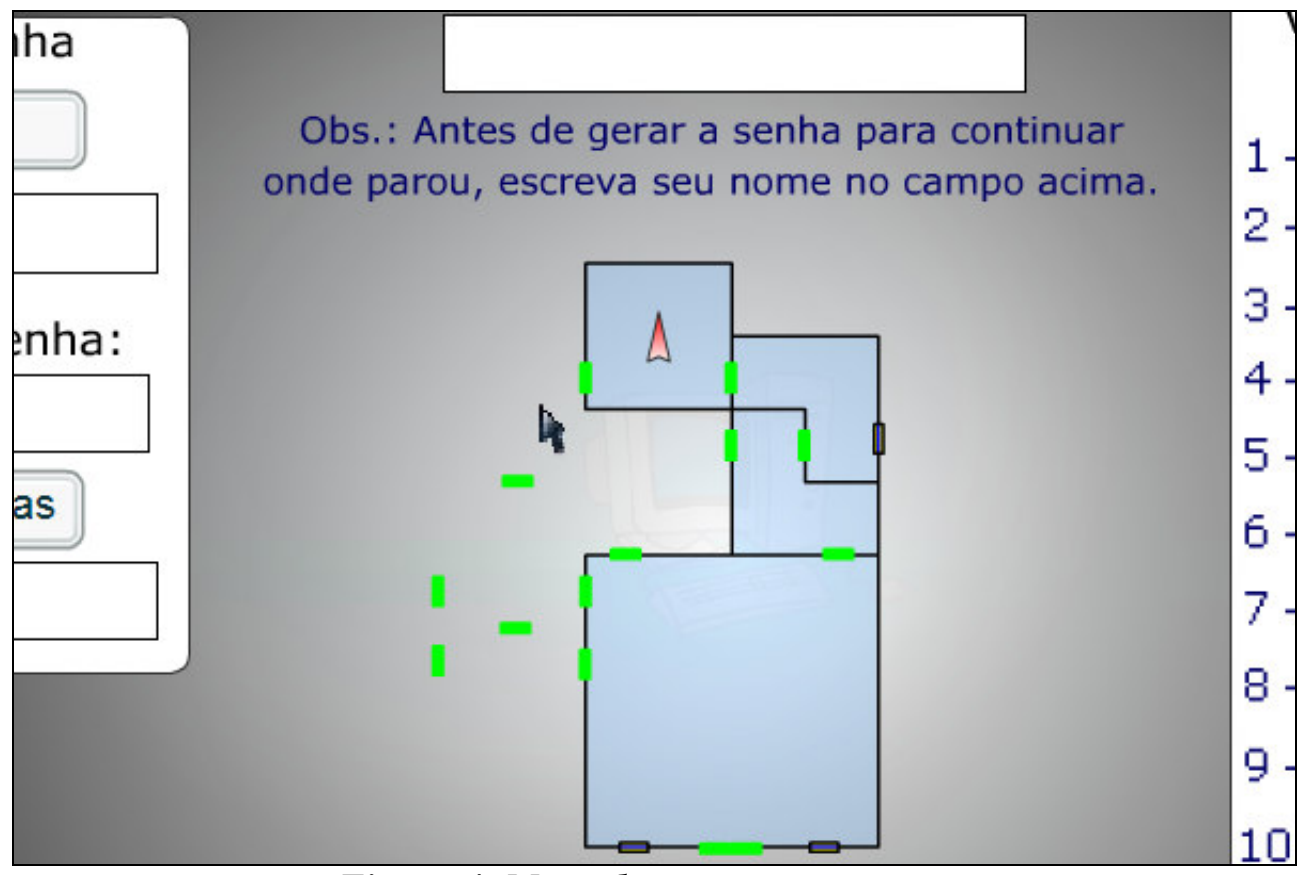

Figura 4: Mapa de navegação <menu>

3.2 Desafios e Conceitos de Matemática e Biologia presentes na Casa dos Desafios:

A Casa dos Desafios possui um total de 9 salas, 12 portas e 16 desafios.

Os desafios contendo conceitos de Matemática e de Biologia estão distribuídos nessas 9 salas, de acordo com as informações da tabela 1 apresentada a seguir.

\begin{tabular}{|l|l|l|l|}
\cline { 2 - 4 } \multicolumn{1}{l|}{} & Nome & Conceitos de Matemática & Conceitos de Biologia \\
\hline 1. & Casa dos Desafios & $\begin{array}{l}\text { - Orientação Espacial } \\
\text { - Noções de Geometria } \\
\text { Espacial } \\
\text { - Grafos } \\
\text { - Análise Combinatória }\end{array}$ & \\
\hline 2. & 4 Cores & $\begin{array}{l}\text { - Teorema das 4 Cores (figura } \\
\text { 5) } \\
\text { - Grafos } \\
\text { - Topologia } \\
\text { - Combinatória } \\
\text { - Aritmética }\end{array}$ & \\
\hline 3. & Curto Circuito & $\begin{array}{l}\text { - Equações } \\
\text { - Sistema de Equações } \\
\text { - Matrizes }\end{array}$ & \\
\hline 4. & Varal de Roupas & & - Evaporação (figura 6) \\
\hline $\mathbf{5 .}$ & Filhotes & & $\begin{array}{l}\text { - reprodução } \\
\text { - espécie } \\
\text { - população } \\
\text { - predação } \\
\text { - fertilização interna } \\
\text { - fertilização externa } \\
\text { - ovo } \\
\text { - placenta }\end{array}$ \\
\hline
\end{tabular}




\begin{tabular}{|c|c|c|c|}
\hline & & & $\begin{array}{l}\text { - girino } \\
\text { - anuro } \\
\text { - seres ovíparos } \\
\text { - seres vivíparos } \\
\text { - reprodução de peixes } \\
\text { - aves, répteis, anfíbios e } \\
\text { mamíferos }\end{array}$ \\
\hline 6. & Aeração & & $\begin{array}{l}\text { - aeração } \\
\text { - matriz orgânica } \\
\text { - carbonatos } \\
\text { - respiração celular } \\
\text { - cromoplastos } \\
\text { - seres autótrofos } \\
\text { - energia luminosa } \\
\text { - turbidez da água } \\
\text { - fotossíntese } \\
\text { - bactérias } \\
\text { - massa } \\
\text { - cloroplasto } \\
\text { - quimiosítese } \\
\text { - detritos } \\
\text { - seres anaeróbicos } \\
\text { - fermentação } \\
\text { - temperatura } \\
\text { - glicose } \\
\text { - algas verdes } \\
\text { - poluentes } \\
\text { - clorofila } \\
\text { - seres aeróbicos } \\
\text { - densidade } \\
\text { - seres heterótrofos } \\
\text { - energia química } \\
\text { - fungos }\end{array}$ \\
\hline 7. & $\begin{array}{l}\text { Medindo o } \\
\text { Inalcançável }\end{array}$ & $\begin{array}{l}\text { - Ângulo } \\
\text { - Triângulo } \\
\text { - Trigonometria }\end{array}$ & \\
\hline 8. & Caça-Bandeiras & - Sistema de Coordenadas & \\
\hline 9. & Peixes no aquário & & $\begin{array}{l}\text { - ambiente marinho } \\
\text { - difusão } \\
\text { - ecossistema } \\
\text { - membrana plasmática } \\
\text { - osmose } \\
\text { - peixes } \\
\text { - osmoregulação } \\
\text { - solução hipotônica } \\
\text { - solução hipertônica } \\
\text { - solução istônica } \\
\text { - transporte ativo }\end{array}$ \\
\hline
\end{tabular}

Tabela 1: Desafios / Conceitos: 


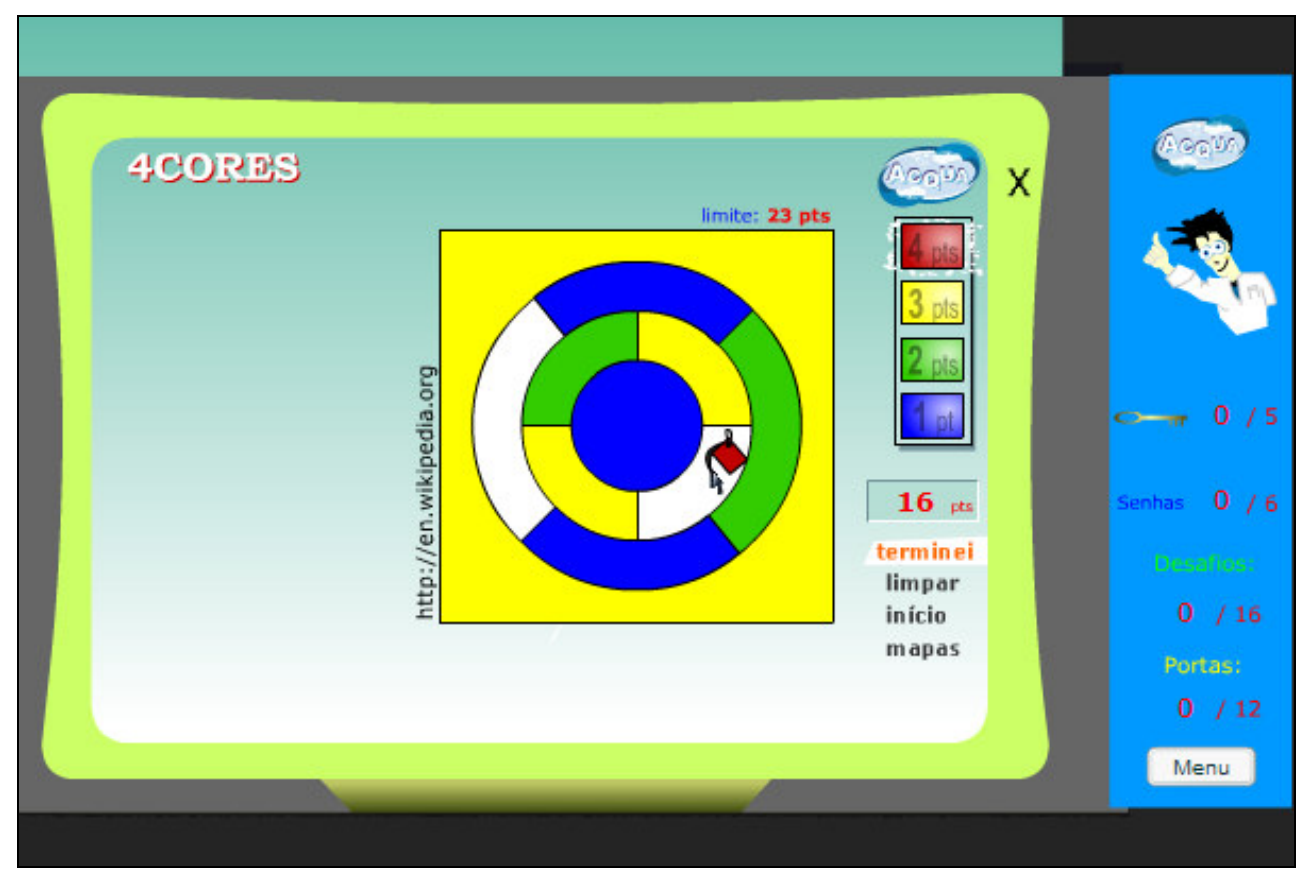

Figura 5: <teorema das 4 cores >

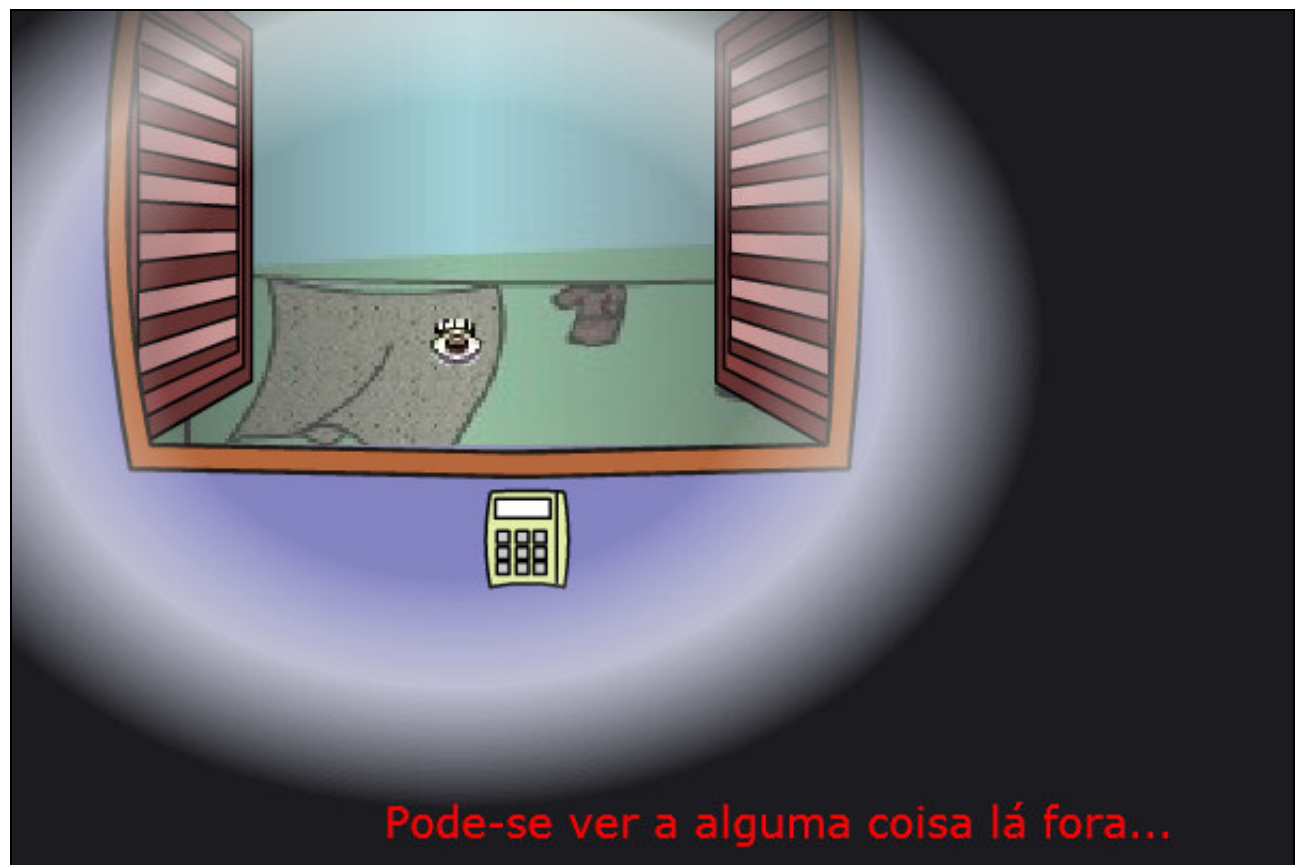

Figura 6: <varal de roupas >

\section{Biologia $x$ Matemática $x$ Modelagem}

É interessante salientar que em se tratando dos fenômenos biológicos, novas abordagens foram necessárias. As simulações e interações entre os elementos dos módulos desenvolvidos exigem um trabalho maior do que as atividades tradicionais de matemática que estávamos acostumados, onde tendemos sempre a uma maior abstração na representação. 
Uma aproximação muito maior da realidade é requerida para evitar mal entendidos nas idéias que estão sendo desenvolvidas. Por exemplo, se queremos nos referir a evaporação relacionada com a secagem de uma roupa num varal (figura 6), temos que representar a roupa molhada/seca, a umidade do ar, os ventos, a pressão e a temperatura apenas para iniciar a discussão ou simular questões relativamente simples que queremos colocar ao aluno.

\section{Conclusão}

A própria representação da Casa dos Desafios e a navegação no seu interior com suas diferentes vistas dá um exemplo da complexidade da representação e da criatividade como fator relevante nesse processo. Encontrar soluções e definir os limites foi um dos aspectos de maior dificuldade, mas, essenciais no desenvolvimento de cada módulo separadamente. Não se chegou a um modelo ou a algum padrão de criação, mas a necessidade de trabalho realimentado a cada momento sob risco de ter que recomeçar várias vezes.

A próxima etapa será levar o OA à escola pra ver como os estudantes avaliam o material produzido até agora. Esperamos encontrar sugestões de todo tipo. Desde pequenos detalhes visuais, erros de programação, erros de digitação entre outros. Também é esperado que surjam sugestões que tornem o material mais interessante. Espera-se que o OA se constitua num material com interface amigável e agradável para quem terá que passar um tempo diante do computador pesquisando. Igualmente importante, desejamos que nesse ambiente, o aluno sinta vontade de explorá-lo e no qual encontre formas de dimensionar e incrementar seus conhecimentos, via simulações de situações de Biologia e de Matemática, encontrando, quem sabe, relações entre esses campos do saber que não percebemos no seu desenvolvimento.

Estamos particularmente interessados em obter informações quanto à aceitação do material, do seu conteúdo e verificar sua abrangência. Precisamos saber quanto e onde devemos aprofundá-lo em termos de conceitos de Matemática e Biologia; quanto e como estimulamos o usuário. Enfim, descobrir como contextualizar e adequar o material ao estudante e seu perfil que é único e, dessa forma, ampliar ainda mais o alcance de utilização do objeto de aprendizagem Casa dos Desafios.

\section{Bibliografia}

BASSO, M. V. A. Espaços de aprendizagem em rede: novas orientações na formação de professores de matemática. Tese de Doutorado. CINTED/PGIE. UFRGS. Porto Alegre, 2003. Disponível em: $<$ http://lec.psico.ufrgs.br/ mbasso/tese> Acesso online em novembro de 2008.

FAGUNDES, L., MAÇADA, D., SATO, L.;. Aprendizes do futuro: as inovações começaram. Coleção Informática para a Mudança na Educação. MEC/ SEED/ ProInfo, 1999.

LEVY, P. As Tecnologias da Inteligência - O Futuro do Pensamento na era da Informática. Editora 34: Rio de Janeiro, 1993.

LUCCHESI, E. M., SILVA, P. A., SILVA, V. T, LIMA, C. L, BASSO, M. V. A., Construindo Objetos de Aprendizagem e pensando em Geometria. UFRGS: Novas Tecnologias na Educação, V. 4 N² 2, Dezembro, 2006. Disponível em: 
$<$ http://www.cinted.ufrgs.br/renote/dez2006/artigosrenote/25135.pdf $>$ Acesso online em novembro de 2008.

LUCCHESI, E. M., SILVA, P. A., JARDIM, R. F., LIMA, C. L, BASSO, M. V. A. Ensinando geometria plana através de mosaicos com a ajuda de um objeto de aprendizagem no padrão RIVED. UFRGS: Novas Tecnologias na Educação, V. 4 No 2, Dezembro, 2004. Disponível em: <http://www.cinted.ufrgs.br/renote/maio2005/artigos/a49_geometriaplana.pdf>. Acesso online em novembro de 2008.

LUCCHESI, E. M., SEIDEL S. Uso de software no ensino-aprendizagem de Matemática. UFRGS: Novas Tecnologias na Educação, V. $2 \mathrm{~N}^{\circ} 1$, Março, 2004. Disponível em: <http://www.cinted.ufrgs.br/renote/mar2004/artigos/34usodesoftware.pdf.> Acesso online em novembro de 2008.

RIVED-IM-LEC-UFRGS. Fábrica Virtual - RIVED - LEC - IM - UFRGS $<$ http://fabricavirtual.lec.ufrgs.br>. Acesso online em novembro de 2008.

MDMat-IM-UFRGS. Projeto Mídias Digitais para Matemática -IM - UFRGS. $<$ http://mdmat.psico.ufrgs.br/acqua $>$. Acesso online em novembro de 2008. 